\title{
DISGUST SENSITIVITY AND GENDER DIFFERENCES: AN INITIAL TEST OF THE PARENTAL INVESTMENT HYPOTHESIS
}

\author{
Pavol Prokop, Milada Jančovičová \\ Trnava University, Trnava, Slovakia \\ E-mail: pavol.prokop@savba.sk, miladka.j@gmail.com
}

\begin{abstract}
It is suggested that the emotion of disgust evolved as a disease protection mechanism in humans. The vast majority of the research revealed that females are consistently more disgust sensitive than males. Certain adaptationists have suggested that gender differences in disgust sensitivity reflect higher parental investment and offspring protection by females as compared with males. We experimentally tested the parental investment hypothesis by manipulating the visual and acoustic exposure of participants to cues associated with parental investment (a picture of an infant's face and the sounds of an infant crying). The control group was exposed to cues that do not trigger parental investment (an adult man speaking a foreign language). It was found that participants in the experimental group did not score higher in the pathogen disgust domain and had similar expected reproductive goals than participants in the control group. Girls and sexually mature participants rated pictures with disease-relevant animals as more disgusting than boys and sexually immature participants. These results provide no support for the role of parental investment as an ultimate explanation for higher disgust sensitivity in females.
\end{abstract}

Key words: disgust, gender, parental investment, sexual maturation.

\section{Introduction}

Disgust is one of the six basic emotions that are universally displayed and recognized (Darwin, 1872). Bodily secretions and excretions, blood, corpses, rotting food, disease-relevant animals and incest are typical stimuli that invoke heightened disgust (Fessler \& Navarrete, 2003; Curtis, Aunger, \& Rabie, 2004; Prokop \& Fančovičová, 2010; Rozin, Haidt, \& McCauley, 2000). These disgust-invoking objects/subjects obviously possess the risk of being contaminated (Curtis \& Biran, 2001; Curtis et al., 2004). Subjects viewing disgust-relevant stimuli show increased brain activation in the occipital-temporal lobe, in the prefrontal cortex, and in the thalamus (Phillips et al., 1997) and amygdala (Stark et al., 2003; Schienle, Schäfer, Walter, Stark, \& Vaitl, 2005b). Neural activity consequently triggers behavioral mechanisms which inhibit disease transmission (Curtis \& Biran, 2001; Curtis et al., 2004). In particular, people exhibit avoidance and/or aversive responses toward disgusting stimuli accompanied by a typical facial expression which is recognizable across cultures (Darwin, 1872; Ekman \& Friesen, 1986; Mesquita \& Frijda, 1992). 
Women are typically more disgust sensitive than men (e.g., Curtis et al., 2004; Davey et al., 1998; Haidt, McCauley, \& Rozin, 1994; Prokop \& Fančovičová, 2010; Schienle, Schäfer, Stark, Walter, \& Vaitl, 2005a, Tybur, Lieberman, \& Griskevicius, 2009; for a review see Oaten, Stevenson, \& Case, 2009), although the neural activity of certain brain centers is similar between the sexes (Stark et al., 2003; Schienle et al., 2005a). Some evidence suggests that elevated levels of the hormone progesterone, which is typical in the luteal phase of the menstrual cycle, positively correlates with disgust sensitivity since progesterone has an immunosuppressive effect on a woman's body (Fessler, 2001; Fessler, Eng, \& Navarrete, 2005; Fleischman \& Fessler, 2011). This suggests that sex hormones influence disgust sensitivity in women.

From an adaptationist view, it could be expected that greater disgust sensitivity in women compared to men is due to women's increased parental investment (Trivers, 1972); while males produce large amounts of sperm cells, females (particularly mammals) invest time and energy into gravidity, lactation and protecting offspring. Thus, it is reasonable to expect that women who care for infants who need to be protected from infectious diseases should be more sensitive to disease-connoting cues (Curtis et al., 2004; Oaten et al. 2009). Incest, as an example of suboptimal sexual behaviour due to the increased likelihood of detrimental homozygotic recessive alleles in offspring (Bittles, 2001), elicit stronger feelings of disgust in females as compared to males (Lieberman, Tooby, \& Cosmides, 2003; Fessler \& Navarrete, 2004; Antfolk, Karlsson, Bäckström, \& Santtila, 2012a; Antfolk, Lieberman, \& Santtila, 2012b). This suggests that greater reproductive costs in human males and females regulates gender differences in disgust responses. However, disgust sensitivity is developed at a very early age in humans (i.e., from 2.5 years, see Stevenson, Oaten, Case, Repacholi, \& Wagland, 2010) and the higher sensitivity of females to disgusting stimuli begins at least by 8 years of age (Prokop \& Fančovičová, 2010). This strongly suggests that caring for infants itself cannot be responsible for higher disgust sensitivity in females and that factors influencing gender differences should be detectable in school-aged children. Parental investment could be a factor that explains this difference between boys and girls. To the best of our knowledge, however, no study has investigated parental investment theory and disgust sensitivity.

\section{Research Focus}

To address this omission, we conducted an experiment in which the following predictions were tested. First, visual and acoustic exposure to stimuli that could trigger parental investment would enhance participants' disgust sensitivity. The rationale for this prediction is supported by the fact that some human brain centres activated upon exposure to infant face and/or infant crying (a caretaking elicitor in all studied mammals) including substantia nigra, amygdala, thalamus, parietal cortex, and prefrontal cortex (e.g., Kim, Mayes, Wang, Leckman, Feldman, \& Swain, 2010; Swain, Lorberbaum, Kose, \& Strathearn, 2007) are similar to those activated by visual exposure to disgust stimuli (e.g., Schienle et al., 2005b; Stark et al., 2003). This suggests that a neurobiological link between parental care and disgust sensitivity could exist. Second, the greater the expected reproductive investment, the higher disgust is expected from cues associated with risk of contamination. Thus, we predicted that, compared to individuals not exposed to parental investment cues, individuals exposed to parental investment cues would react with more disgust to cues associated with contamination. Third, in line with previous studies and with parental investment theory, females should show increased sensitivity to disease-relevant cues, but not to disease-irrelevant (control) cues (Prokop, Fančovičová, \& Fedor 2010a; Prokop, Usak, \& Fančovičová, 2010b,c). Finally, if heightened disgust sensitivity in females is influenced by parental investment and related hormonal shifts, then sexually mature females should be more disgust sensitive than their sexually immature counterparts. To date, no published research has investigated the effect of sexual maturation on disgust sensitivity in humans. 


\title{
42 Methodology of Research
}

\author{
Sample of Research
}

The sample of participants ( 75 males and 72 females, four participants excluded) consisted of 10-15-year-olds $(\mathrm{M}$ yrs $=11.8, \mathrm{SE}=0.11)$ attending one elementary school in Western Slovakia. Our previous research (Prokop \& Fančovičová, 2010; Prokop et al., 2010c) revealed that children of at least 8 years of age are sensitive to cues which pose a disease threat to humans; thus, 10 year old children seem to be appropriate for testing our hypotheses. Moreover, this group of participants consisted of children with similar age, thus our investigation was focused almost exclusively on hormonal (i.e., sexually mature and sexually immature), rather than on age differences between participants. The participants were asked to provide their age/grade and sex.

\section{Instrument and Procedures}

\section{Disgust inducing visual cues of pathogens}

We presented 16 colour pictures in lecture halls to groups of students. Each picture contained one insect and was presented individually. Overall, eight out of the sixteen pictures presented to each participant were insects, either disease-relevant (head lice [Pediculus capitis], hard tick [Ixodes ricinus], human flea [Pulex irritans] and mosquito [Anopheles gambiae]), or their disease-irrelevant antipoles (Old World swallowtail [Papilio machaon], ladybird beetle [Coccinella septempunctata], leaf beetle [Chrysomela fastuosa] and azure damselfly [Coenagrion puella]). Similar invertebrates were used by Prokop and Fančovičová (2010). Images of objects holding a potential disease threat were taken from a published study examining people's perception of pathogens (Curtis et al., 2004) and recently used by Little et al. (2011) and Prokop et al. (2012). Each high pathogen image had a low pathogen counterpart. For example, a plate of viscous liquid colour-morphed like bodily fluids (high pathogen cue) or a blue chemical dye (low pathogen cue). In this study, the remaining pictures were: a healthy and unhealthy male face (low and high pathogen cue, respectively), a white cloth with a stain resembling body fluid (high pathogen cue) or a strain of blue liquid (low pathogen cue), and a metro (i.e., a subway) that was either full of people or empty (low and high pathogen cue, respectively). Pictures were adjusted to identical sizes. The pictures had a similar contrast and brightness. The pictures were presented in random order. Each picture was presented for 30 seconds. During this time, participants rated disgust of presented pictures (e.g., How disgusting would you consider this animal?) on a 5 -point scale $(1=$ not at all, $5=$ extremely disgusting $)$. When pre-test data of all participants $(\mathrm{n}=147)$ were pooled together, the test-retest reliability was high (Guttman split-half reliability $=0.87$. We calculated individual scores for disgusting pictures (DP, pictures with disgusting animals and high pathogen cues pooled) and control pictures (CP, pictures with control animals and low pathogen cues pooled) by averaging the responses to the constituent items.

\section{Parental investment}

To induce the activity of specific brain centers which influence parental behavior toward children, we used a 1 min long video block with a 3 month old baby boy crying. Participants watching this video (the experimental group) were consequently exposed to both visual (a baby face) and acoustic (crying) stimuli which trigger parental investment. The control group was shown a neutral video with a 30 year old man from the news who spoke a foreign language (Portuguese). None of the participants reported knowledge of Portuguese; thus, the content of the video could not be understood. The control group was thereby also shown both a visual and acoustic stimuli produced by a human although neither of them were expected to enhance parental investment. Both videos were freely downloaded from available web sites. The length of the visual/acoustic exposure to the was similar to other studies that have shown significantly influenced neural activity in human brains (e.g., 30 seconds: Lorberbaum et al., 1999; 40 seconds: Ranote et al., 2004). 
There is general agreement that the emotion of disgust has three relatively independent domains: Pathogen Disgust (PD) refers to disgust elicitors caused by the sources of various pathogens (e.g., stepping in dog excrement). Moral Disgust (MD) refers to disgust that pertains to social transgressions (e.g., deceiving a friend). These social transgressions broadly include non-normative, often antisocial activities such as cheating, stealing, etc. Sexual Disgust (SD) refers to disgust which motivates sexual avoidance of an unsuitable mating partner or other reproductively costly behavior (e.g., performing anal sex or being in a situation with a high probability of having sex with a stranger). We were particularly interested in pathogen disgust and, consequently, decided to use the Pathogen Disgust (PD) domain adopted from Tybur et al. (2009). We also measured Moral Disgust (MD) adopted from the same questionnaire (Tybur et al., 2009) in order to examine, whether possible changes caused by the experimental manipulation will influence the PD domain, but not the MD domain. Both the PD and MD subscales consist of seven Likert scale items ( $1=$ not at all disgusting, $5=$ =xtremely disgusting). Examples of the items are: Stepping in dog excrement, Stealing from a neighbor, respectively. The PD and MD domains had acceptable pre-test and post-test reliabilities (Cronbach's alpha for the $\mathrm{PD}$ domain $=0.64$ and 0.76 ; Cronbach's alpha for the MD domain $=0.81$ and 0.83 , respectively). When pre-test data of all participants $(n=147)$ were pooled together, the test-retest reliability was high (Guttman split-half reliability $=0.80)$. We calculated the individual scores of DP and MD by averaging the responses to the constituent items.

\section{Sexual maturity}

We asked one question ("Have you had your first menstrual cycle?") in order to examine the onset of sexual maturity (generally defined as the age when an organism can reproduce) in girls. Girls that reported having had their first menstruation were treated as sexually mature $(\mathrm{M}=12.4$, $\mathrm{SD}=1.16, \mathrm{n}=39$ ) and girls that reported not having had their first menstruation were treated as sexually immature $(\mathrm{M}=11.1, \mathrm{SD}=0.75, \mathrm{n}=33)$. The onset of sexual maturity in males is much harder to estimate unless a physical assessment by a physician is performed, but reported data suggest that Caucasian boys mature somewhat later than girls (e.g. Sun, Schubert, \& Chumlea et al., 2002). Consequently, we decided to classify 5 th and 6 th grade boys as sexually immature $(\mathrm{M}=10.9, \mathrm{SD}$ $=0.65, \mathrm{n}=49)$, as the majority of the females in these grades $(72 \%)$ were also sexually immature. Boys from the $7^{\text {th }}$ and $8^{\text {th }}$ grades were treated as sexually mature $(\mathrm{M}=13.6, \mathrm{SD}=0.81, \mathrm{n}=26)$. Participants did not know about our hypotheses. After the research was completed, the participants were debriefed regarding the research goals.

\section{Expected Reproductive Goals (ERG)}

ERG was measured by asking participants "How many children would you like to have in the future MAXIMUM" and "How many children would you like to have in the future MINIMUM?" (see Wang, Kruger, \& Wilke, 2009). Responses to these two questions were moderately correlated $(\mathrm{r}=0.46, \mathrm{p}<0.001)$ and, thus were combined and then averaged.

\section{Experimental Procedure}

Participants were randomly divided into experimental and control groups and were tested two times: before (pre-test) and after treatment (post-test). In the pre-test, all the participants completed a questionnaire which consisted of the Disgusting Pictures (DP), Control Pictures (CP), Pathogen Disgust (PD), Moral Disgust (MD) and Expected Reproductive Goals (ERG) scales as well as basic demographic variables and measure of sexual maturity (females only). Four weeks after the pre-test, we presented cues influencing parental investment (CIPI) to the participants from the experimental group. Post-test questionnaires were administered immediately after the experiment. The control group was exposed to the neutral video. 


\section{Data Analysis}

A 2 (treatment: between-subject) $\times 2$ (gender: between-subject) $\times 2$ (sexual maturity: betweensubject) multivariate analysis of covariance (MANCOVA) with five dependent variables (postest mean scores of DP, CP, PD, MD and ERG scales) was used to examine whether there are effects of treatment, gender and sexual maturity on disgust sensitivity and expected reproductive goals. A series of t-tests indicated there were no differences in pre-test mean scores between the experimental and the control group in the DP, CP, PD and ERG scales (all $p>0.09$ ), although the control group tended to score higher in the MD scale $(t=2.04, p=0.04)$. Thus, the pre-test scores of the MD scale was treated as a covariate to check for potentially confounding pre-test differences between the two groups. Between-subject interactions between the variables were not statistically significant (all $p$ $>0.1$ ) and were consequently not mentioned in the text. Partial $\eta^{2}$ was used in order to measure the effect size (0.01 was considered small, 0.04 moderate, and 0.10 large; Huberty, 2002)

\section{Results of Research}

\section{Effects of Experimental Procedure, Gender and Sexual Maturity}

MANCOVA revealed that there was a significant effect of gender (Wilks's $\lambda=0.89, \mathrm{~F}(5,134)$ $\left.=3.24, p=0.008, \eta^{2}=0.11\right)$ on the dependent variables. However, effects of treatment and sexual maturity were not statistically significant (Wilks's $\lambda=0.97$ and $0.94, F(5,134)=0.95$ and $1.57, \mathrm{p}=$ 0.45 and $0.17, \eta^{2}=0.03$ and 0.06 , respectively). Interactions between variables were also not significant (all $\mathrm{p}>0.49$, all $\eta^{2} \leq 0.032$ ). A series of ANCOVAs revealed no gender differences in ERG, MD, PD and $\mathrm{CP}\left(\mathrm{F}(1,138)=0.70,0.0009,2.28\right.$ and 0.013 , all $\mathrm{p}>0.13$, all $\eta^{2} \leq 0.016$, respectively $)$. Girls, however, scored significantly higher in the DP domain $\left(\mathrm{F}(1,138)=11.07, \mathrm{p}=0.001, \eta^{2}=\right.$ 0.07 , Table 1). A detailed analysis of univariate results for the effect of sexual maturity that showed a moderate effect size revealed that sexually mature participants had higher mean score in the DP domain than sexually immature participants $\left(\mathrm{F}(1,138)=4.40, \mathrm{p}=0.04, \eta^{2}=0.03\right)$. Other differences were not statistically significant.

Table 1. Differences in expected reproductive goals (ERG), moral disgust (MD), pathogen disgust (PD), ratings of disgusting pictures (DP) and control pictures (CP) with respect to treatment, gender and sexual maturity.

\begin{tabular}{cccccccccccccccc}
\hline & & & \multicolumn{2}{c}{ ERG } & \multicolumn{2}{c}{ MD } & & PD & & DP & \multicolumn{3}{c}{ CP } & \\
\hline \multirow{2}{*}{ Treatment } & Gender & $\begin{array}{c}\text { Sexual } \\
\text { maturity }\end{array}$ & $\mathbf{M}$ & SD & M & SD & M & SD & M & SD & M & SD & $\mathbf{n}$ \\
\hline Experimental & Boys & Immature & 1.74 & 0.72 & 3.38 & 1.06 & 3.58 & 0.93 & 3.48 & 0.99 & 1.89 & 0.70 & 25 \\
& & Mature & 1.39 & 0.55 & 3.11 & 0.74 & 4.29 & 0.50 & 4.10 & 0.53 & 2.29 & 0.52 & 9 \\
& Girls & Immature & 1.71 & 0.42 & 4.03 & 0.84 & 4.03 & 0.77 & 4.06 & 0.70 & 2.14 & 0.50 & 19 \\
& & Mature & 1.67 & 0.71 & 3.57 & 0.71 & 3.98 & 0.75 & 4.28 & 0.47 & 2.16 & 0.57 & 18 \\
Control & Boys & Immature & 1.73 & 0.63 & 3.93 & 0.86 & 3.52 & 1.01 & 3.51 & 0.91 & 1.92 & 0.74 & 24 \\
& & Mature & 1.76 & 0.73 & 3.37 & 0.93 & 3.61 & 0.70 & 3.79 & 0.50 & 2.10 & 0.69 & 17 \\
& Girls & Immature & 1.75 & 0.61 & 4.01 & 0.69 & 3.88 & 0.45 & 4.29 & 0.60 & 1.92 & 0.59 & 14 \\
& & Mature & 1.69 & 0.56 & 3.55 & 0.80 & 3.91 & 0.72 & 4.08 & 0.48 & 2.06 & 0.54 & 21 \\
\hline
\end{tabular}

\section{Correlations between the Domains}

Scores on the PD strongly correlated with scores on the DP, and moderately with scores on the CP (Table 2). However, scores on the MD subscale did not correlate with the DP, CP, or PD subscale (Table 2). These findings suggest that the PD subscale is independent from the MD subscale.

Because the parental investment hypothesis is based on reproductive investment, we further 
investigate whether there are any associations between the ERG and other domains. The ERG did not correlate with MD, PD, DP, or CP both in the pre-test and the post-test (Table 2).

Table 2. Pearson correlations between five domains ( $n=147$ participants). Pretest $r$ values are below the diagonal and post-test $r$ values are above the diagonal. Asterisks denote statistically significant correlations ( $* p<$ $0.05, * * \mathrm{p}<0.01, * * \mathrm{p}<0.001)$.

\begin{tabular}{cccccc}
\hline & ERG & MD & PD & DP & CP \\
ERG & & -0.1 & -0.06 & 0.01 & 0.02 \\
MD & -0.16 & & $0.17^{*}$ & $0.27^{* *}$ & 0.12 \\
PD & -0.02 & -0.06 & & $0.61^{* * *}$ & $0.42^{* * *}$ \\
DP & -0.02 & 0.09 & $0.62^{* * *}$ & & $0.53^{* * *}$ \\
CP & 0.14 & 0.02 & $0.48^{* * *}$ & $0.64^{* * *}$ & \\
\hline
\end{tabular}

\section{Discussion}

This study investigated gender differences in disgust sensitivity from an evolutionary perspective. As far as we are aware, this is the first study which attempted to experimentally test whether parental investment theory accounts for differences in disgust sensitivity in human males and females.

The first predictions derived from the parental investment hypothesis suggest that visual and acoustic exposure to stimuli which trigger parental investment should enhance participants' disgust sensitivity and that ERG should correlate with disgust sensitivity. This study provided no statistical support for these predictions. Specifically, participants exposed to the video with crying children evidenced levels of disgust similar to those reported by participants in the control group. In particular, children exposed to the video with crying children showed a similar pathogen disgust than the children in the control group and considered pictures with insects (both disease-relevant and control) similarly disgusting as did participants in the control group. One explanation for this lack of effect may be that mother's responses to the cries had been found to vary with respect to inter-personal differences between mothers (Ainsworth et al., 1978) and are increasingly sensitized to repeated infant distress signals (Out, Pieper, Bakermans-Kranenburg, \& van IJzendoorn, 2010). Babies crying may also trigger certain aversive responses (Swain et al., 2007), resulting in abuse, neglect and infanticide (Soltis, 2004). The present study, however, did not control for inter-personal differences in participant's responses to the cries. Furthermore, we used a single visual and acoustic exposure to stimuli that trigger neural activity (Lorberbaum et al., 1999; Ranote et al., 2004), but the question whether a more intense, repeated exposure to the crying children would stimulate stronger emotional response, remains open.

The largely negative results could also be explained by the age and by experience of the participants. Kim et al. (2010) in their study on adult mothers with a mean age of approximately 33 revealed that the postpartum period is accompanied by structural changes in brain regions, such as increased gray matter volumes in large regions of the prefrontal cortex, parietal lobe, and midbrain similarly as it has been found with rat mothers (e.g., Featherstone, Fleming, \& Ivy, 2000). It is possible that the experimental manipulation employed in the present study (i.e. audiovisual stimuli of a crying baby) did not increase sentiments pertaining to parental investment in the participants. Thus, the fact that we were unable to detect any differences in disgust sensitivity between the experimental group and the control group should not be taken as a falsification of the hypothesis that differences in male and female parental investment explain the differences in male and female disgust sensitivity. There are no studies, however, which investigate changes in neural activity after exposure to baby faces and/or crying amongst humans of a comparable age as in the present research (P. Kim, pers. comm.). In other words, it remains unclear whether the manipulation led to any changes in neural activity. Thus, it is hard to assess the degree of neural activity after the treatment in the present work. The possibility that the postpartum and parental experience could make parents more disgust sensitive cannot be ruled out. 
OF PSYCHOLOGY

IN THE $21^{\text {st }}$ CENTURY Volume 7, 2013

46

Further research in both neurobiological and behavioral level in this area is clearly required.

The third prediction replicates previous research suggesting that women are more disgust sensitive than men (for a review see Oaten et al., 2009). Girls scored significantly higher in the DP domain, but not in the PD domain. It may be that visual cues of pathogens produce more valid measurements than the paper-and-pencil test (the PD domain) (Rozin, Haidt, McCauley, Dunlop, \& Ashmore, 1999).

The final prediction suggested that sexually mature individuals should be more disgust sensitive than their sexually immature counterparts, because heightened disgust would help them protect offspring against threat of disease. This prediction received some support since sexually mature individuals scored significantly higher than sexually immature individuals in the DP domain. This indirectly supports current research indicating that hormonal shifts correlate with disgust sensitivity in humans (Fessler, 2001; Fessler et al., 2005; Fleischman \& Fessler, 2011). Overall, higher disgust sensitivity in sexually mature individuals is compatible with the parental investment hypothesis.

\section{Conclusion}

This study provided little support for the hypothesis that higher parental investment is associated with heightened disgust sensitivity which primarily protects humans against disease transmission. Participants exposed to a baby crying and face scored similarly in all domains than control participants. It is possible that the present study experimentally did not induce parental investment in such a way, thus no differences between the experimental and control group could be detected. Sexually mature individuals who are more likely to reproduce were more disgust sensitive the DP domain than their sexually immature counterparts. Further research should be focused on adult individuals who vary in their parental experience and the effect of the postpartum period on disgust sensitivity in humans.

\section{Acknowledgments}

Daniel M. T. Fessler made helpful comments on previous versions of the manuscript. David Livingstone improved the English of the manuscript.

\section{References}

Ainsworth, M. S., Blehar, M. C., Waters, E., \& Wall, S. (1978). Patterns of attachment: A psychological study of the strange situation. Potomac, Md: Lawrence Erlbaum.

Antfolk, J., Karlsson, M., Bäckström, A., \& Santtila, P. (2012a). Disgust elicited by third- party incest: the roles of biological relatedness, co-residence, and family relationship. Evolution and Human Behavior, 33, 217-223. doi: 10.1016/j.evolhumbehav.2011.09. 005.

Antfolk, J., Lieberman, D., \& Santtila, P. (2012b). Fitness costs predict inbreeding aversion irrespective of self-involvement: Support for hypotheses derived from evolutionary theory. PLoS ONE, 7, e50613. doi: 10.1371/journal.pone.0050613.

Bittles, A. (2001). Incest, inbreeding and their consequences. In N. J. Smelser \& P. B. Baltes (Eds.), International encyclopedia of the social \& behavioral sciences, Vol. 11. (pp. 7254-7259). Oxford: Pergamon.

Curtis, V., Aunger, R., \& Rabie, T. (2004). Evidence that disgust evolved to protect from risk of disease. Biology Letters, 272, S131-S133. doi: 10.1098/rsbl.2003.0144

Curtis, V., \& Biran, A. (2001). Dirt, disgust, and disease: Is hygiene in our genes? Perspectives in Biology and Medicine, 44, 17-31. doi: 10.1353/pbm.2001.0001.

Darwin, C. (1872). The expression of the emotions in man and animals.: London: John Murray.

Ekman, P., \& Friesen, W. V. (1986). A new pan-cultural facial expression of emotion. Motivation and Emotion, 10, 159-168.

Davey, G. C. L., McDonald, A. S., Hirisave, U., Prabhu, G. G., Iwawaki, S., Jim, C. I., Merckelbach, H., de Jong, P. J., Lejny, P. W. L., \& Reimann, L. (1998). A cross - cultural study of animal fears. Behaviour Research \& Therapy, 36, 735-750. doi: 10.1016/S0005-7967(98)00059-X.

Featherstone, R. E., Fleming, A. S., \& Ivy, G. O. (2000). Plasticity in the maternal circuit: Effects of experience and partum condition on brain astrocyte number in female rats. Behavioral Neuroscience, 114, 158-172. 
doi: $10.1037 / 0735-7044.114 .1 .158$.

Fessler, D. M. T. (2001). Luteal phase immunosuppression and meat eating. Rivista di Biologia, 94, 403426.

Fessler, D. \& Navarette, C. (2003). Domain specific variation in disgust sensitivity across the menstrual cycle: evidence in favour of an evolutionary account of sexual disgust. Evolution and Human Behavior, 24, 406-417. doi: 10.1016/S1090-5138(03)00054-0.

Fessler, D. M. T., \& Navarrete, C. D. (2004). Third-party attitudes towards sibling incest: evidence for Westermarck's hypotheses. Evolution and Human Behavior, 25, 277-294. doi: 10.1016/S10905138(04)00040-6.

Fessler, D. M. T., Eng, S. J., \& Navarrete, C. D. (2005). Elevated disgust sensitivity in the first trimester of pregnancy: Evidence supporting the compensatory prophylaxis hypothesis. Evolution and Human Behavior, 26, 344-351. doi:10.1016/j.evolhumbehav. 2004.12.001.

Fleischman, D.S., \& Fessler, D. M. T. (2011). Progesterone's effects on the psychology of disease avoidance: support for the compensatory behavioral prophylaxis hypothesis. Hormones and Behavior, 59, 271-275. doi: 10.1016/j.yhbeh.2010.11.014.

Haidt, J., McCauley, C. R., \& Rozin, P. (1994). Individual differences in sensitivity to disgust: a scale sampling seven domains of disgust elicitors. Personality and Individual Differences, 16, 701-713. doi: 10.1016/0191-8869(94)90212-7.

Huberty, C. J. (2002). A history of effect sizes indices. Educational and Psychological Measurement, 62, 227-240. doi: 10.1177/0013164402062002002

Kim, P., Mayes, L.C., Wang, X., Leckman J.F., Feldman R., Swain J.E. (2010). The plasticity of human maternal brain: longitudinal changes in brain anatomy during the early postpartum period. Behavioral Neuroscience, 124, 695-700. doi: 10.1037/a0020884

Lieberman, D., Tooby, J., \& Cosmides, L. (2003). Does morality have a biological basis? An empirical test of the factors governing moral sentiments relating to incest. Proceedings of the Royal Society of London, 270, 819-826. doi: 10.1098/rspb.2002.2290.

Little, A. C., DeBruine, L. M., \& Jones, B. C. (2011). Exposure to visual cues of pathogen contagion changes preferences for masculinity and symmetry in opposite-sex faces. Proceedings of the Royal Society of London, 1714, 2032-2039. doi: 10.1098/rspb. 2010.1925

Lorberbaum, J. P., Newman, J. D., Dubno, J. R., Horwitz, A. R., Nahas, Z., Teneback, C. C., Bloomer, C. W., Bohning, D. E., Vincent, D., Johnson, M. R., Emmanuel, N., Brawman-Mintzer, O., Book, S. W., Lydiard, R. B., Ballenger, J. C., \& George, M. S. (1999). Feasibility of using fMRI to study mothers responding to infant cries. Depression and Anxiety, 10, 99-104. doi: 10.1002/(SICI)1520-6394.

Mesquita, B. \& Frijda, N. H. (1992). Cultural variation in emotions: a review. Psychological Bulletin, 11, 179-204. doi: 10.1037//0033-2909.112.2.179.

Oaten, M., Stevenson, R. J., \& Case, T. I. (2009). Disgust as a disease-avoidance mechanism. Psychological Bulletin, 135, 303-321. doi: 10.1037/a0014823.

Out, D., Pieper, S., Bakermans-Kranenburg, M. J., \& van IJzendoorn, M. H. (2010). Physiological reactivity to infant crying: a behavioral genetic study. Genes, Brain and Behavior, 9, 868-876. doi: 10.1111/j.1601183X.2010.00624.x.

Phillips, M. L., Young A. W., Senior, C., Brammer, M., Andrew, C., Calder, A. J., Bullmore, E. T., Perrett, D. I., Rowland, D., Williams, S. C. R., Gray, J. A., David, A. S. (1997). A specific neural substrate for perceiving facial expressions of disgust. Nature, 389, 495-498. doi: 10.1038/39051.

Prokop, P., \& Fančovičová, J. (2010). The association between disgust, danger and fear of macroparasites and human behaviour. Acta Ethologica, 13, 57-62. doi: 10.1007/s10211-010-0075-4.

Prokop, P., Fančovičová, J., \& Fedor, P. (2010a). Health is associated with anti-parasite behavior and fear of disease-relevant animals in humans. Ecological Psychology, 22, 222-237. doi: 10.1080/10407413.2010.496676.

Prokop, P., Usak, M., \& Fančovičová, J. (2010b). Risk of parasite transmission influences perceived vulnerability to disease and perceived danger of disease-relevant animals. Behavioural Processes, 85, 52-57. doi: 10.1016/j.beproc.2010.06.006.

Prokop, P., Usak, M., \& Fančovičová, J. (2010c). Health and the avoidance of macroparasites: A preliminary 
cross-cultural study. Journal of Ethology, 28, 345-351. doi: 10.1007/s10164-009-0195-3.

Prokop, P., Rantala, M.J., \& Fančovičová, J. (2012). Is plasticity in mating preferences adapted to perceived exposure to pathogens? Acta Ethologica, 15, 135-140. doi: 10.1007/s10211-011-0118-5.

Ranote, S., Elliott, R., Abel, K.M., Mitchell, R., Deakin, J. F., \& Appleby, L. (2004). The neural basis of maternal responsiveness to infants: An fMRI study. NeuroReport, 15, 1825-1829. doi: 10.1097/01. wnr.0000137078.64128.6a.

Rozin, P., Haidt, J., \& McCauley, C. (2000). Disgust. In M. Lewis \& J. M. Haviland (Eds.), Handbook of emotions (pp. 637-653). New York: Guilford Press.

Rozin, P., Haidt, J., McCauley, C., Dunlop, L., \& Ashmore, M. (1999). Individual differences in disgust sensitivity: comparisons and evaluations of paper-and-pencil versus behavioral measures. Journal of Research in Personality, 33, 330-351. doi: 10.1006/jrpe.1999.2251.

Schienle, A., Schäfer, A., Stark, R., Walter, B., \& Vaitl, D. (2005a). Gender differences in the processing of disgust- and fear-inducing pictures: an fMRI study. Neuroreport, 16, 277-280. doi: 10.1097/00001756200502280-00015.

Schienle, A., Schäfer, A., Walter, B., Stark, R., \& Vaitl, D. (2005b). Relationship between disgust sensitivity, trait anxiety and brain activity during disgust induction. Neuropsychobiology, 51, 86-92. doi: $10.1159 / 000084165$.

Soltis, J. (2004). The signal functions of early infant crying. Behavioral and Brain Sciences, 27, 443-490.

Stark, R., Schienle, A., Walter, B., Kirsch, P., Sammer, G., Ott, U., Blecker, C., \& Vaitl, D. (2003). Hemodynamic responses to fear- and disgust-inducing pictures. International Journal of Psychophysiology, 50, 225-234. doi: 10.1016/S0167-8760(03)00169-7.

Stevenson, R. J., Oaten, M. J., Case, T. I., Repacholi, B. M., \& Wagland, P. (2010). Children's response to adult disgust elicitors: Development and acquisition. Developmental Psychology, 46, 165-177. doi: 10.1037/a0016692.

Sun, S. S., Schubert, C. M., Chumlea, W. C., Roche, A. F., Kulin, H. E., Lee, P. A., Himes, J. H., Ryan, A. S. (2002). National estimates of the timing of sexual maturation and racial differences among US children. Pediatrics, 110, 911-919. doi: 10.1542/peds.110.5.911.

Swain, J. E., Lorberbaum, J. P., Kose, S., \& Strathearn, L. (2007). Brain basis of early parent-infant interactions: Psychology, physiology, and in vivo functional neuroimaging studies. Journal of Child Psychology and Psychiatry, 48, 262-287. doi: 10.1111/j.1469-7610.2007.01731.x.

Trivers, R. L. (1972). Parental investment and sexual selection. In B. Campbell (Ed.), Sexual selection and the descent of man (pp. 136-179). Chicago: Aldine.

Tybur, J. M., Lieberman, D., \& Griskevicius, V. (2009). Microbes, mating, and morality: Individual differences in three functional domains of disgust. Journal of Personality and Social Psychology, 97, 103-122. doi: $10.1037 / \mathrm{a} 0015474$.

Wang, X. T., Kruger, D. J., \& Wilke, A. (2009). Life history variables and risk-taking propensity. Evolution and Human Behavior, 30, 77-84. doi: 10.1016/ j.evolhumbehav.2008.09.006.

Advised by Irena Gailiene, SMC "Scientia Educologica", Lithuania

Received: November 10, 2013

Accepted: November 30, 2013

Pavol Prokop PhD., Associate Professor, Department of Biology, Faculty of Education, Trnava University, Priemyselná 4, 91843 Trnava, Slovakia.

E-mail: pavol.prokop@savba.sk

Website: http://www.zoo.sav.sk/prokopo 